\title{
BMJ Open Sex-specific mortality prediction by pro- C-type natriuretic peptide measurement in a prospective cohort of patients with ST-elevation myocardial infarction
}

\author{
Peter D Mark, ${ }^{1}$ Martin Frydland (1) ,, Ole Kristian Lerche Helgestad (D) , ${ }^{3}$ \\ Lene Holmvang, ${ }^{3}$ Jacob Eifer Møller, ${ }^{3}$ Pär I Johansson (10 , ${ }^{4}$ Sisse R Ostrowski, ${ }^{4}$ \\ Timothy Prickett, ${ }^{5}$ Christian Hassager, ${ }^{2}$ Jens Peter Goetze (D) ${ }^{1,6}$
}

To cite: Mark PD, Frydland M, Helgestad OKL, et al. Sexspecific mortality prediction by pro-C-type natriuretic peptide measurement in a prospective cohort of patients with ST-elevation myocardial infarction. BMJ Open 2021;11:e048312. doi:10.1136/ bmjopen-2020-048312

- Prepublication history and additional supplemental material for this paper are available online. To view these files, please visit the journal online (http://dx.doi.org/10.1136/ bmjopen-2020-048312)

Received 22 December 2020 Accepted 17 September 2021

Check for updates

(c) Author(s) (or their employer(s)) 2021. Re-use permitted under CC BY-NC. No commercial re-use. See rights and permissions. Published by BMJ.

For numbered affiliations see end of article.

Correspondence to Dr Jens Peter Goetze; JPG@dadlnet.dk

\section{ABSTRACT}

Objective To determine the predictive value of pro-C-type natriuretic peptide (pro-CNP) measurement in plasma sampled on admission from patients presenting with STelevation myocardial infarction (STEMI).

Design Prospective cohort study.

Setting Two University Hospitals in Denmark.

Participants 1760 consecutive patients (470 females and 1290 males) with confirmed STEMI.

Main outcomes and measures The main outcome was all-cause mortality at 1 year after presentation and the primary measure was pro-CNP concentration in plasma at admission in all patients and longitudinal measurements in a consecutive subgroup of 287 patients. A reference population $(n=688)$ defined cut-off values of increased pro-CNP concentrations.

Results In all patients, an increased pro-CNP concentration was associated with a higher allcause mortality after 1 year (HR 1.6, 95\% $\mathrm{Cl} 1.1$ to $2.4, P_{\text {logrank }}=0.009$ ) including an interaction of sex $(p=0.03)$. In separate sex-stratified analyses, female patients showed increased all-cause mortality ( $\mathrm{HR}_{1}$ year $2.6,95 \% \mathrm{Cl} 1.5$ to 4.6 ), $\mathrm{P}_{\text {logrank }}<0.001$ ), whereas no differences were found in male patients $\left(\mathrm{HR}_{1 \text { year }}\right.$ $1.1,95 \% \mathrm{Cl} 0.7$ to $\left.1.9, \mathrm{P}_{\text {logrank }}=0.66\right)$. After adjusting for potential risk factors, we found increased pro-CNP concentrations $\geq$ the median value to be independently associated with increased risk of mortality in female patients within 1 year (HR per 1 pmol/L increase: 1.04 , $95 \% \mathrm{Cl} 1.01$ to $1.06, p=0.007)$. Moreover, we found indications of sex differences in pro-CNP concentrations over time (higher pro-CNP in males $(4.4,95 \% \mathrm{Cl}-0.28$ to $9.1 \mathrm{pmol} / \mathrm{L}, \mathrm{p}=0.07$ ) and interaction of sex and time $(p=0.13))$, and that hypertension was independently associated with higher pro-CNP $(4.5,95 \% \mathrm{Cl} 0.6$ to 8.4 $\mathrm{pmol} / \mathrm{L}, \mathrm{p}=0.03$ ).

Conclusions In female but not male patients presenting with STEMI, high concentrations of pro-CNP ( $\geq$ median) at admission independently indicate a higher risk of all-cause mortality. The findings are remarkably specific for female patients, suggesting a different vascular phenotype beyond traditional measures of coronary artery flow compared with male patients.

\section{Strengths and limitations of this study}

- The is the first study to investigate the prognostic potential of measurement of peptides derived from pro-C-type natriuretic peptide (pro-CNP) by using predefined sex-specific and age-specific cut-off values based on a reference population.

- As a novel approach, a large cohort of patients are examined during the acute phase of ST-elevation myocardial infarction with plasma sampling at admission and all-cause mortality within 1 year as main outcome.

- To clarify the temporal pattern of pro-CNP concentrations, longitudinal measurements during admission in a subgroup of the cohort are used to further examine sex differences and baseline associations.

- The sex-specific analyses are exploratory and the present report should be considered a hypothesisgenerating study.

- As all-cause mortality within 1 year is the only available outcome measure, other clinical end-points and long-term follow-up is not investigated.

\section{INTRODUCTION}

Despite the structural resemblance to the cardiac hormones, atrial A-type natriuretic peptides (ANP) and B-type natriuretic peptides, C-type natriuretic peptide (CNP) differ functionally from the two other family members. ${ }^{1}$ CNP is a paracrine/autocrine peptide expressed in many tissues, ${ }^{2}$ including endothelial cells. ${ }^{3}$ Experimental studies have shown that endothelial-derived CNP is locally involved in regulation of vascular tone ${ }^{45}$ and angiogenesis. ${ }^{6}$ Also, a recent preclinical investigation has suggested that CNP plays a key protective role in cardiac pathophysiology. ${ }^{7}$

Clinical reports on the general population as well as patients with heart disease have examined circulating pro-CNP-derived peptides as prognostic markers. ${ }^{8-10}$ In patients presenting with acute coronary syndrome, 
high concentrations of amino-terminal pro-CNP (NT-pro-CNP) in plasma measured 4-6 weeks after the event were reported to be the only natriuretic peptide to independently predict cardiac readmission and death in the patients with unstable angina. ${ }^{8}$ Taken together, experimental and epidemiological data suggest CNP to be an important regulator of cardiovascular function and that increased concentrations of pro-CNP-derived peptides in plasma of patients reflect an unfavourable cardiovascular condition as a compensatory response to cardiovascular disease. However, no previous large study has explored the prognostic value of measurement of pro-CNP-derived peptides in the acute phase of an ST-elevation myocardial infarction (STEMI). ${ }^{11}$

In this study, we measured concentrations of the precursor of pro-CNP in plasma from a large cohort of patients presenting with STEMI, where baseline blood samples were collected when patients were admitted (before coronary intervention). Previously, we have reported on this method for accurate quantification of 'total' pro-CNP in plasma by a processing-independent radioimmunoassay. ${ }^{12}$ We determined pro-CNP concentration as a predictor of all-cause mortality within 1 year and examined for potential sex differences. Moreover, we investigated a large consecutive subgroup of patients with STEMI from the cohort with longitudinal plasma samples collected during the hospital admission to examine proCNP concentrations over time and further analyse baseline associations between pro-CNP concentrations and vascular diseases. Finally, we included a large sample of healthy individuals in order to, independently of the patient cohort, establish age-specific and sex-specific reference intervals for pro-CNP concentrations in plasma.

\section{Nomenclature}

Pro-CNP: In the present article, pro-CNP refers to a specific amino-acid sequence (human pro-CNP 11-27) within the prohormone sequence of CNP; the epitope of the antiserum of our radioimmunoassay. In this processing-independent methodology, we use this fragment after enzymatic cleavage in vitro as a proxy measure of all proforms released to plasma irrespective of prohormone post-translational processing.

Pro-CNP-derived peptides: Collective term for any fragment of the prohormone of CNP.

\section{METHODS}

\section{Reference population}

For establishment of reference intervals, we used plasma samples from the Nordic Reference Interval Project Biobank and Database, originally consisting of 3002 subjects. ${ }^{13}$ A subgroup of 853 subjects from this population was randomly selected with the aim to represent sex, age and country of origin equally, as previously described. ${ }^{14}$

\section{Cohort of patients with STEMI}

Patients with suspected STEMI were consecutively included from two Danish hospitals over a period of 1 year
(2015/2016) (Copenhagen University Hospital, Rigshospitalet and Odense University Hospital). The procedure of inclusion has been described previously. ${ }^{15}$ From this cohort of patients with suspected STEMI and triaged for acute coronary angiography (CAG) (based on assessment of symptoms and the individual ECG), we only included patients with confirmed STEMI. ${ }^{16}$ All patients underwent CAG and baseline blood samples were obtained immediately before CAG was performed (see further details on data collection including blood sampling in online supplemental material.

\section{Patient and public involvement}

Patients and/or the public were not involved in the design, or conduct, or reporting, or dissemination plans of this research.

Patients gave written informed consent. When patients were not able to provide this (eg, comatose cardiac arrest patients), consent was obtained by the patients' next of kin and general practitioners in accordance with national legislation.

\section{Biochemical analyses}

Plasma pro-ANP and pro-CNP concentrations were quantified by the previously reported processing-independent assay technology and procedures. ${ }^{12} 1718$ Information of other biochemical analyses can be found in online supplemental material.

\section{All-cause mortality}

The Danish Civil Registration System was used for allcause mortality assessment. All Danish citizens are recorded with a unique 10-digit civil registration number, and deaths are registered within 2 weeks. Initial follow-up began on the date of admission and continued until date of death, or 30 October 2017.

\section{Main outcomes}

The primary outcome was 1-year all-cause mortality. We tested 30-day all-cause mortality as a secondary outcome. We focused on sex-specific estimates as we found a statistical interaction of sex and pro-CNP concentrations on mortality.

\section{Study design}

The study design is summarised in figure 1 .

\section{Statistics}

Reference population

We divided the reference population into groups based on sex and age ( $<50$ and $\geq 50$ years) and used the RefVal software $^{19}$ to calculate $95 \%$ reference intervals based on a non-parametric bootstrapping method. See online supplemental table 1 for results on reference intervals.

\section{STEMI cohort}

Based on their respective sex-specific and age-specific reference interval from the reference population, all STEMI patients were stratified according to (A) increased 


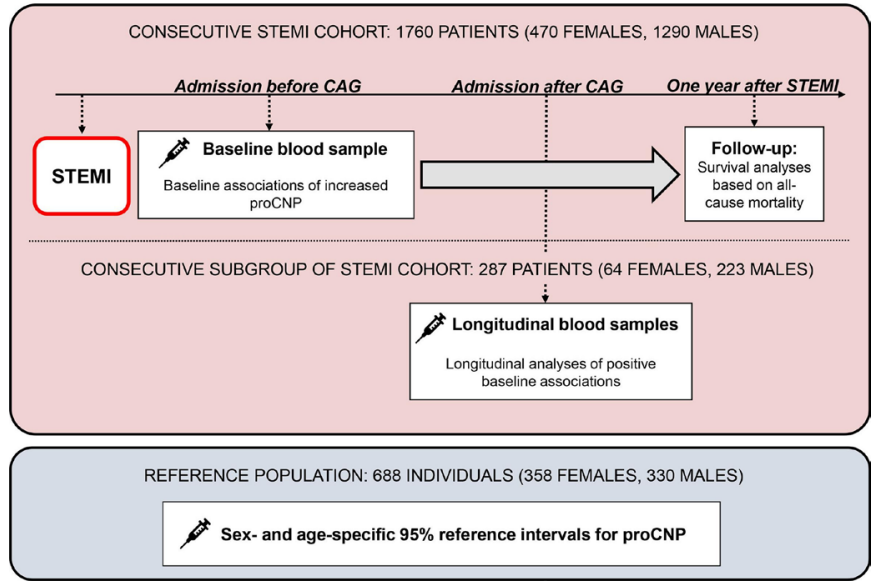

Figure 1 Study design. CAG, coronary angiography; proCNP, pro-C-type natriuretic peptide (see the Nomenclature section); STEMI, ST-elevation myocardial infarction.

pro-CNP concentration (higher than the $95 \%$ reference interval), (B) normal pro-CNP concentration (within the $95 \%$ reference interval) and (C) decreased pro-CNP concentration (lower than the $95 \%$ reference interval). Dichotomous variables are presented as numbers $(\mathrm{n})$ and percentages $(\%)$. Continuous variables are presented as medians with 25-75th percentiles. Comparisons between groups were done using independent non-parametric t-tests and Fisher's exact two-sided test. Spearman's correlation analyses were used to assess the relationships between pro-CNP and other biochemical analytes. Differences in median pro-CNP concentrations at different time intervals from onset of symptoms to blood sample were assessed by Kruskal-Wallis tests (this time parameter also reflects total ischaemic time; see online supplemental material). All-cause mortality after 30 days and 1 year was assessed in patients stratified into normal or increased pro-CNP concentrations and depicted by Kaplan-Meier plots and then compared with the log-rank test and estimates of HR including $95 \%$ CIs. We performed a statistic test of interaction between sex and groups of pro-CNP. To test the relation of mortality and pro-CNP concentrations on a continuous scale, we performed cubic spline plots with the density distribution and the logarithm of HRs. We focused our further mortality analyses on pro-CNP concentrations $\geq$ median, where we observed an effect of increasing pro-CNP concentrations on mortality (patients were divided into groups of $\geq$ vs $<$ median pro-CNP according to sex-specific and age-specific median proCNP concentrations of the reference population shown in online supplemental material. Thus, for patients with a baseline pro-CNP concentration $\geq$ median, multivariable Cox proportional hazard models including pro-CNP, age, plasma creatinine, plasma pro-ANP, time from onset of symptoms to blood sample, number of coronary vessels affected and tertiles of peak plasma troponin concentrations were constructed for mortality assessment. Both plasma pro-ANP and creatinine were logarithmically transformed, where peak troponin $\mathrm{T}$ and troponin $\mathrm{I}$ were combined in one variable of tertiles (represented by values of one to three) as a proxy myocardial infarction size, before being entered into the model. For longitudinal analyses, we constructed four time points/intervals for statistical analyses (1: samples from admission; 2 : 1-12 hours after admission; 3: $>12$ to 24 hours after admission; 4:>24 hours after admission). We used linear mixed models of unstructured covariances to examine changes in concentrations and associations with co-variables over time. Statistical analyses were performed using RefVal software V.20 for calculation of reference intervals, statistical software R V.3.6.1 (R Core Team, Vienna, Austria ${ }^{20}$ ) for linear mixed models (nlme package), and IBM SPSS Statistics V.22 (SPSS) for other analyses. A p $<0.05$ was considered statistically significant.

\section{RESULTS}

\section{Reference population}

We measured pro-CNP concentrations in available plasma from 688 subjects (358 females; 330 males). From these measurements, $95 \%$ reference intervals for females versus males and $<\mathrm{vs} \geq 50$ years were calculated (see results in online supplemental table 1).

\section{STEMI cohort}

From the cohort of 2247 patients with suspected STEMI, 1760 patients (460 females and 1290 males) with verified STEMI and available plasma were included in our study (see a flow chart of the inclusion in online supplemental figure 1) and the relative frequencies of measured proCNP concentrations in online supplemental figure 2). When compared with the sex-specific and age-specific reference intervals, a total of $283(16.1 \%)$ of the patients had an increased pro-CNP concentration; no difference in sex-specific proportions was observed $(\mathrm{p}=0.42)$.

\section{Baseline analyses}

Table 1 shows the baseline characteristics and follow-up in patient groups defined by normal or increased proGNP concentrations. Five patients (one male and four females) displayed decreased pro-CNP concentrations and were not included in table 1. Missing individual information on each variable in each group was between $0.1 \%$ and $4.4 \%$, except for age, sex, mortality, cardiogenic shock, cardiac arrest coma, time from onset of symptoms to blood sample and thrombolysis in myocardial infarction (TIMI) grade flow, where information from all patients was available (see online supplemental table 2) for results on culprit vessel, number of coronary vessels affected and TIMI grade flow). Female patients with increased pro-CNP concentrations at admission had a higher prevalence of hypertension $(p=0.003)$, diabetes mellitus $(p=0.022)$, peripheral artery disease $(p=0.002)$ and chronic kidney disease $(\mathrm{CKD})(\mathrm{p}<0.001)$, whereas male patients had higher prevalence of hypertension $(p=0.004)$, stroke $(p=0.012)$ and CKD $(p<0.001)$. Increased pro-CNP was associated with higher concentrations of 
는,

紊

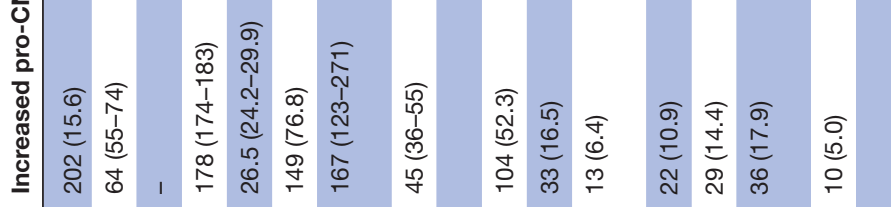

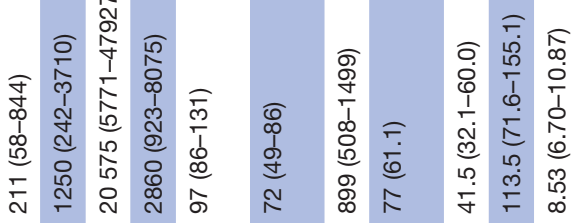

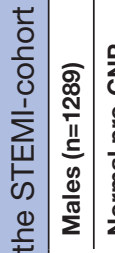

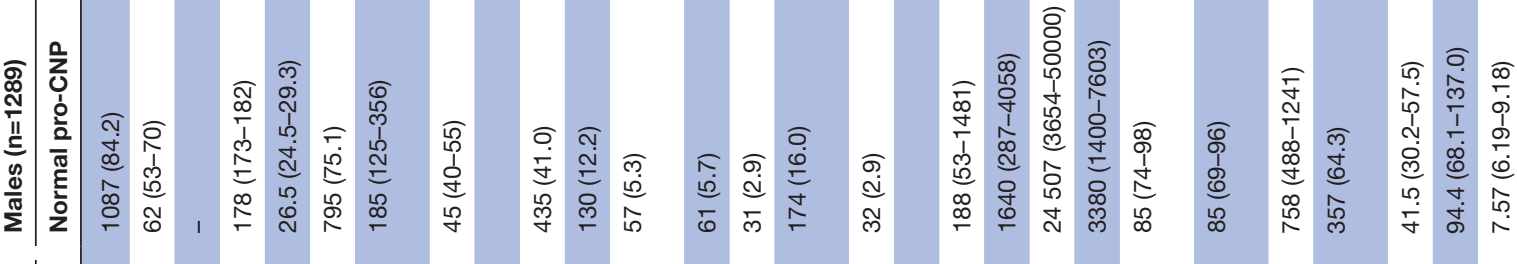

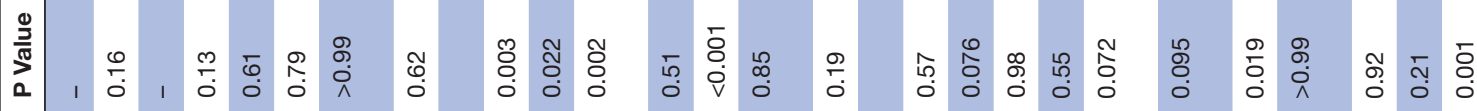

妾

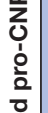

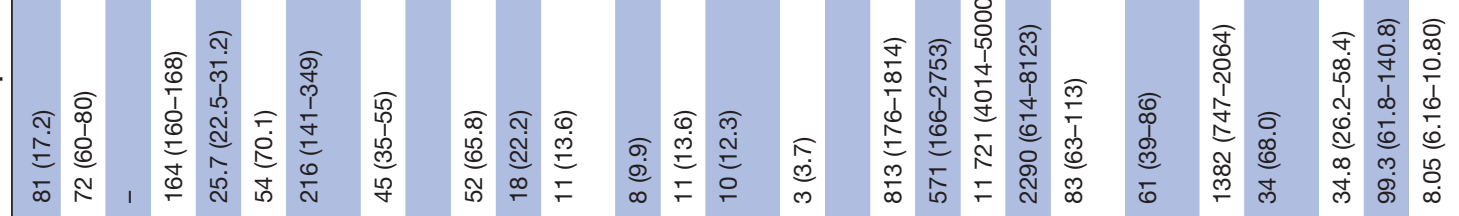

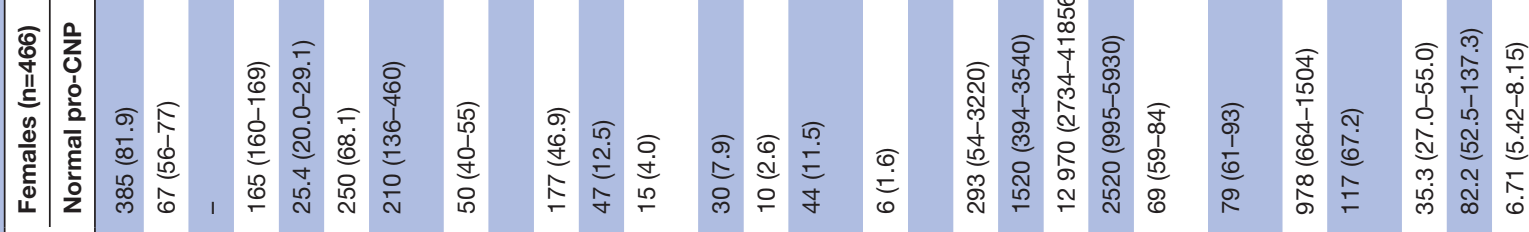

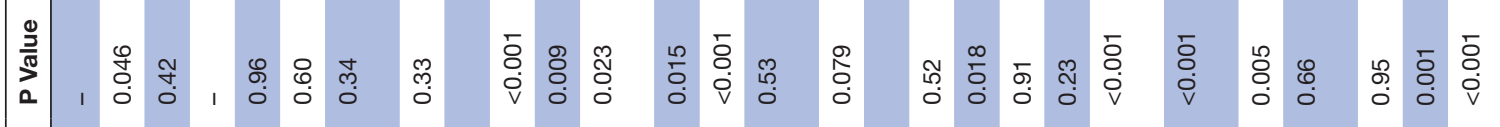

紊

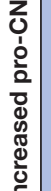

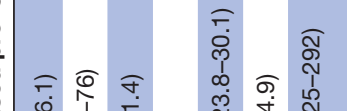

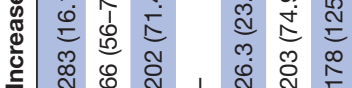

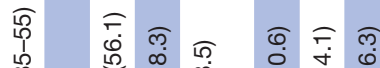

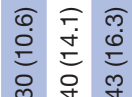

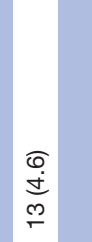

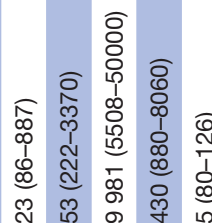

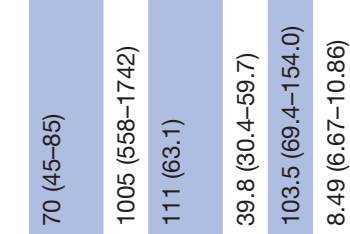

II

$\frac{0}{0}$
$\frac{\pi}{\pi}$
$\frac{\pi}{0}$
$\frac{0}{0}$

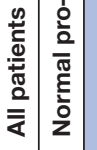

ल

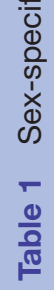

ले ल

वृ

$\begin{array}{llll}\frac{d}{6} & \frac{0}{N} & \frac{N}{N}\end{array}$

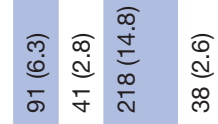

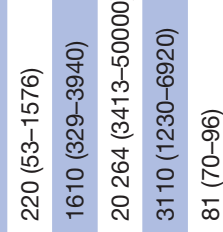

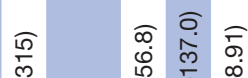

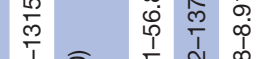

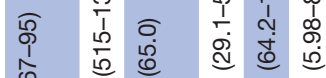

贾 $\underset{\infty}{\mathbb{N}}$ 孛

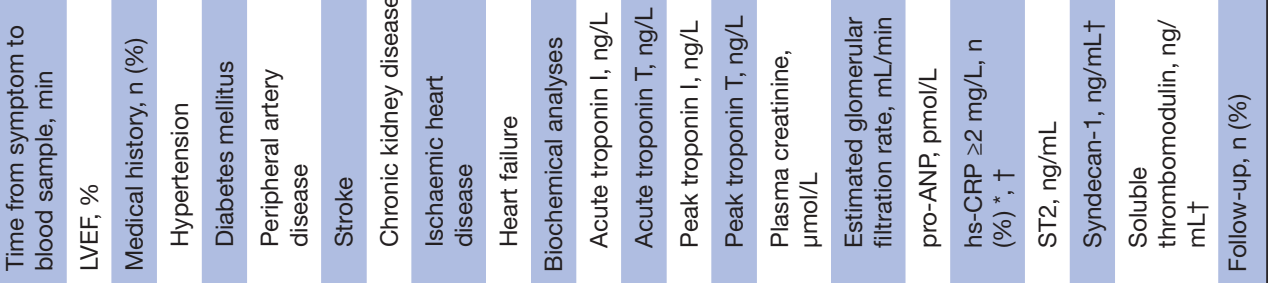


pro-ANP ( $\mathrm{p}=0.019)$ and soluble thrombomodulin ( $\mathrm{sTM})$ $(\mathrm{p}=0.001)$ in female patients and with higher concentrations of creatinine $(\mathrm{p}<0.001)$, syndecan-1 $\quad(\mathrm{p}=0.019)$ and sTM $(\mathrm{p}=0.003)$ in male patients. Lastly, we found a higher 1-year mortality rate $(p=0.001)$ and prevalence of cardiogenic shock development $(p=0.013)$ in female patients with increased pro-CNP concentrations, whereas no differences were found in male patients. For biochemical markers with positive associations to pro-CNP, we performed Spearman's correlation analyses (see online supplemental material for results). For results on median pro-CNP concentrations in groups of time from onset of symptoms to blood sample, see online supplemental material and online supplemental figure 3 .

\section{Mortality analyses}

Thirty days and 1-year all-cause mortality plots of normal and increased pro-CNP concentrations of all patients and stratified by sex are depicted in figure 2. Different mortality rates were found for all patients at both time points $\left(\mathrm{HR}_{30 \text { days }} 1.6,95 \%\right.$ CI 1.0 to 2.6$), \mathrm{P}_{\text {logrank }}=0.03$ and $\mathrm{HR}_{1 \text { year }}=1.6,95 \%$ CI 1.1 to $\left.2.4, \mathrm{P}_{\text {logrank }}=0.009\right)$. However, we found an interaction of sex and groups of pro-CNP $(\mathrm{p}=0.03)$. In sex-specific estimates, only female patients showed different mortality rates (females ${ }_{30 \text { days }}$ : HR 2.8, $95 \%$ CI 1.4 to $5.6, \mathrm{P}_{\text {logrank }}=0.002$, females $1_{\text {year }}:$ HR $2.6,95 \%$ CI 1.5 to $4.6, \mathrm{P}_{\text {logrank }}<0.001$, males $_{30 \text { days }}$ : HR $1.1,95 \%$ CI 0.6 to $2.1, \mathrm{P}_{\text {logrank }}=0.87$, and males ${ }_{1 \text { year }}$ : HR $1.1,95 \%$ CI 0.7 to $\left.1.9, \mathrm{P}_{\text {logrank }}=0.66\right)$. In cubic spline plots, we observed an effect of increasing pro-CNP as a continuous variable on mortality from median concentrations in both sexes. We, therefore, focused on this upper range of pro-CNP concentrations in Cox regression analyses (see online supplemental figure 4). In a univariate Cox proportional hazard model, we found an elevated HR of all-cause mortality with increases of plasma pro-CNP for both sexes (results shown in table 2). When including age and plasma creatinine in a multivariable model (model 1 ), pro-CNP was independently associated with mortality in female but not in male patients (see table 2): HR $(95 \%$ CI) for female patients was 1.04 (1.01 to 1.07) ( $\mathrm{p}=0.008)$ for 30 days and 1.03 (1.01 to 1.06) $(\mathrm{p}=0.010)$ for 1-year mortality, whereas HR was 1.00 for both all patients and male patients at both time points (see table 2). In a model where pro-ANP, tertiles of peak troponins, number of vessels affected, and time from onset of symptoms to admission were also added (model 2), risk estimates of pro-CNP (pr. 1 pmol/L increase) were: HR $(95 \%$ CI $)=1.04$ (1.01 to 1.07$), \mathrm{p}=0.016$ for 30 -day mortality, and HR $(95 \%$ $\mathrm{CI})=1.04$ (1.01 to 1.06 ), $\mathrm{p}=0.007$ for 1-year mortality.

\section{Longitudinal analyses}

To examine pro-CNP concentrations over time during an STEMI and further test the baseline associations of vascular disease and increased pro-CNP, we used a set of longitudinal plasma samples from a consecutive subgroup of the cohort consisting of 287 STEMI patients ( 64 females and 223 males). Results are shown in figure 3, table 3. An 
A

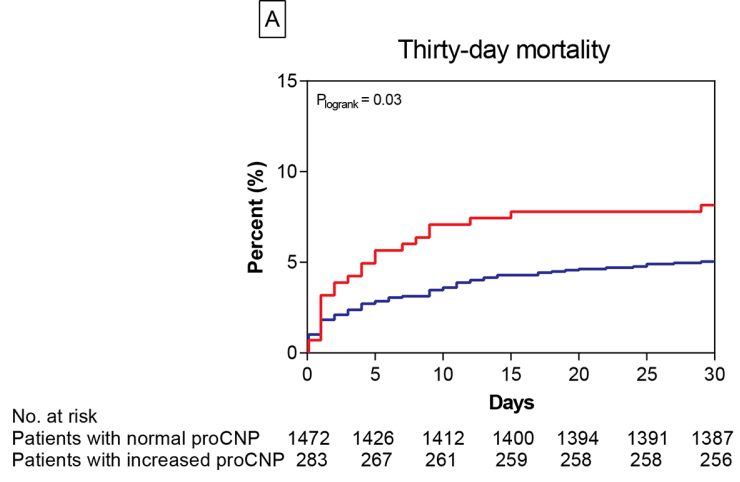

C

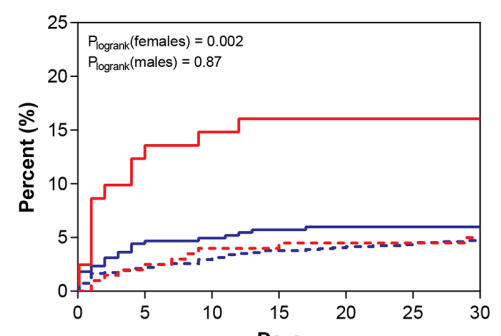

No. at risk

$\begin{array}{lllllllll}\text { Females with normal proCNP } & 385 & 366 & 364 & 361 & 360 & 360 & 360\end{array}$ $\begin{array}{lccccccc}\text { Females with increased proCNP } & 81 & 71 & 69 & 68 & 68 & 68 & 68 \\ \text { Male } & 1087 & 1060 & 1048 & 1039 & 1034 & 1029 & 1027\end{array}$ $\begin{array}{lllllllll}\text { Males with normal proCNP } & 1087 & 1060 & 1048 & 1039 & 1034 & 1029 & 1027 \\ \text { Men } & 202 & 196 & 192 & 191 & 190 & 190 & 188\end{array}$
$B$

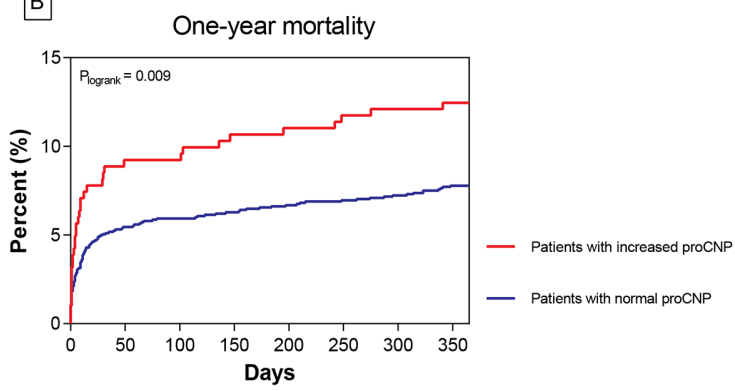

$\begin{array}{llllllll}1472 & 1381 & 1374 & 1369 & 1363 & 1359 & 1355 & 1347\end{array}$ $\begin{array}{llllllll}283 & 253 & 253 & 249 & 248 & 246 & 245 & 244\end{array}$

D

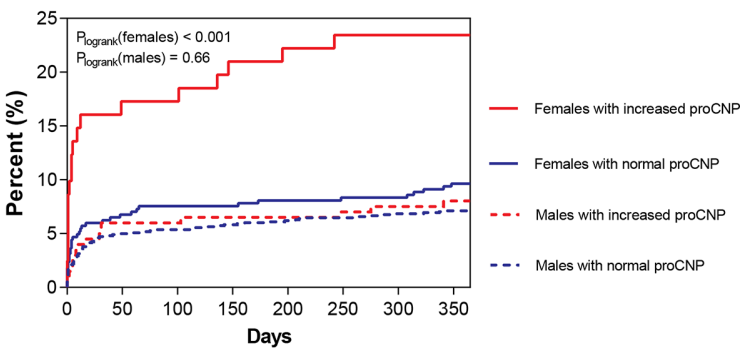

$\begin{array}{llllllll}385 & 357 & 354 & 354 & 352 & 351 & 351 & 346\end{array}$ $\begin{array}{llllllll}81 & 67 & 67 & 64 & 63 & 62 & 62 & 62\end{array}$ $\begin{array}{lllllllll}1087 & 1024 & 1020 & 1015 & 1011 & 1008 & 1004 & 100 \\ 202 & 186 & 186 & 185 & 185 & 184 & 183 & 182\end{array}$

Figure 2 Mortality rates for increased and normal pro-CNP in all patients and stratified by sex. Display of all-cause mortality rates for groups of normal versus increased pro-CNP concentrations in plasma. Graphs of 30-day and 1-year mortality rate for all patients are shown in A and B, respectively. Sex-specific 30-day and 1-year mortality rates are shown in C and D, respectively. The numbers of patients at risk in subgroups are given beneath each graph. CNP, C-type natriuretic peptide.

overall decrease in pro-CNP concentration was estimated to be $3.8 \mathrm{pmol} / \mathrm{L}(\sim 10 \%) \quad(\mathrm{p}=0.001)$ from admission to $>24$ hours. In a multivariate model including sex, age and chronic diseases (model 3), CKD and hypertension were independently associated with higher concentrations of pro-CNP ( $<<0.001$ and $\mathrm{p}=0.03$, respectively), whereas time and age were not independently associated with changes in pro-CNP. Also, both models 2 and 3 implied a positive association of pro-CNP concentration and male sex, and an interaction of time and sex; however, the

Table 2 Cox regression analyses of all-cause mortality

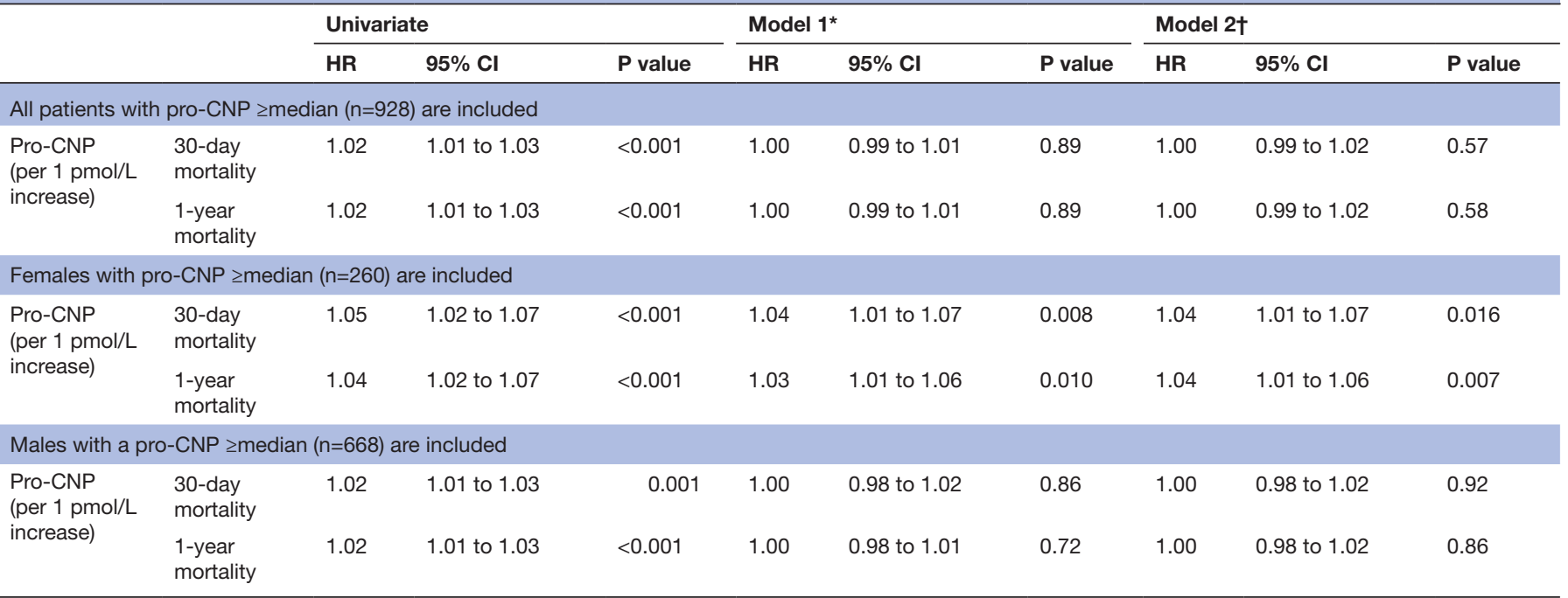

All patients with a pro-CNP $\geq$ median of the sex-specific and age-specific reference interval are included in the analyses to test the predictive value of pro-CNP as a continuous variable (per $1 \mathrm{pmol} / \mathrm{L}$ increase).

*Multivariable model with age and plasma creatinine included as covariables.

†Multivariable model with age, plasma creatinine, pro-ANP, tertiles of peak troponins, number of vessels affected, and time from onset of symptoms to blood sample included as covariables.

ANP, atrial A-type natriuretic peptides; CNP, C-type natriuretic peptide. 
Table 3 Linear mixed models of longitudinal measurements of pro-CNP in 287 patients with STEMI

\begin{tabular}{|c|c|c|c|c|c|c|}
\hline & \multicolumn{2}{|l|}{ Univariate model } & \multicolumn{2}{|c|}{ Multivariate model 1} & \multicolumn{2}{|c|}{ Multivariate model 2} \\
\hline & Value $(95 \% \mathrm{Cl}) / \mathrm{pmol} / \mathrm{L}$ & $P$ value & $\begin{array}{l}\text { Value }(95 \% \\
\mathrm{Cl}) / \mathrm{pmol} / \mathrm{L}\end{array}$ & $P$ value & $\begin{array}{l}\text { Value }(95 \% \mathrm{Cl}) / \\
\mathrm{pmol} / \mathrm{L}\end{array}$ & P value \\
\hline Time (per time point) & $-1.3(-2.1$ to -0.5$)$ & 0.001 & $\begin{array}{l}-0.25(-1.8 \\
\text { to } 1.3)\end{array}$ & 0.75 & $-0.25(-1.8$ to 1.3$)$ & 0.76 \\
\hline Age (per year) & Variables not included & & $\begin{array}{l}0.16(0.02 \text { to } \\
0.30)\end{array}$ & 0.02 & $\begin{array}{l}0.06(-0.08 \text { to } \\
0.20)\end{array}$ & 0.39 \\
\hline $\begin{array}{l}\text { Sex (effect of male } \\
\text { sex) }\end{array}$ & & & $\begin{array}{l}4.5(-0.6 \text { to } \\
9.6)\end{array}$ & 0.09 & $4.4(-0.28$ to 9.1$)$ & 0.07 \\
\hline $\begin{array}{l}\text { Interaction of time } \\
\text { and sex }\end{array}$ & & & $\begin{array}{l}-1.4(-3.2 \text { to } \\
0.4)\end{array}$ & 0.13 & $-1.4(-3.2$ to 0.36$)$ & 0.13 \\
\hline $\begin{array}{l}\text { Chronic kidney } \\
\text { disease }\end{array}$ & & & Variables not & included & 19.7 (13.3 to 26.1$)$ & $<0.001$ \\
\hline Hypertension & & & & & 4.5 (0.6 to 8.4$)$ & 0.03 \\
\hline Diabetes & & & & & $-4.0(-9.7$ to 1.7$)$ & 0.17 \\
\hline $\begin{array}{l}\text { Peripheral artery } \\
\text { disease }\end{array}$ & & & & & $-5.1(-13.9$ to 3.7$)$ & 0.26 \\
\hline Stroke & & & & & $2.7(-5.3$ to 10.7$)$ & 0.51 \\
\hline
\end{tabular}

The table shows the associated estimated changes in pro-CNP concentration in $\mathrm{pmol} / \mathrm{L}(95 \% \mathrm{Cl})$ when each variable is entered in a linear mixed model. All variables included in the models are shown in the table.

CNP, C-type natriuretic peptide; STEMI, ST-elevation myocardial infarction.

statistical uncertainty of these estimates was substantial $(\mathrm{p}=0.07$ and $\mathrm{p}=0.13$, respectively). Figure 3 shows proCNP concentrations over time in overall and sex-specific graphs including graphs of CKD and hypertension (see online supplemental material, online supplemental table
3 and online supplemental figure 5 for further results of longitudinal measurements).
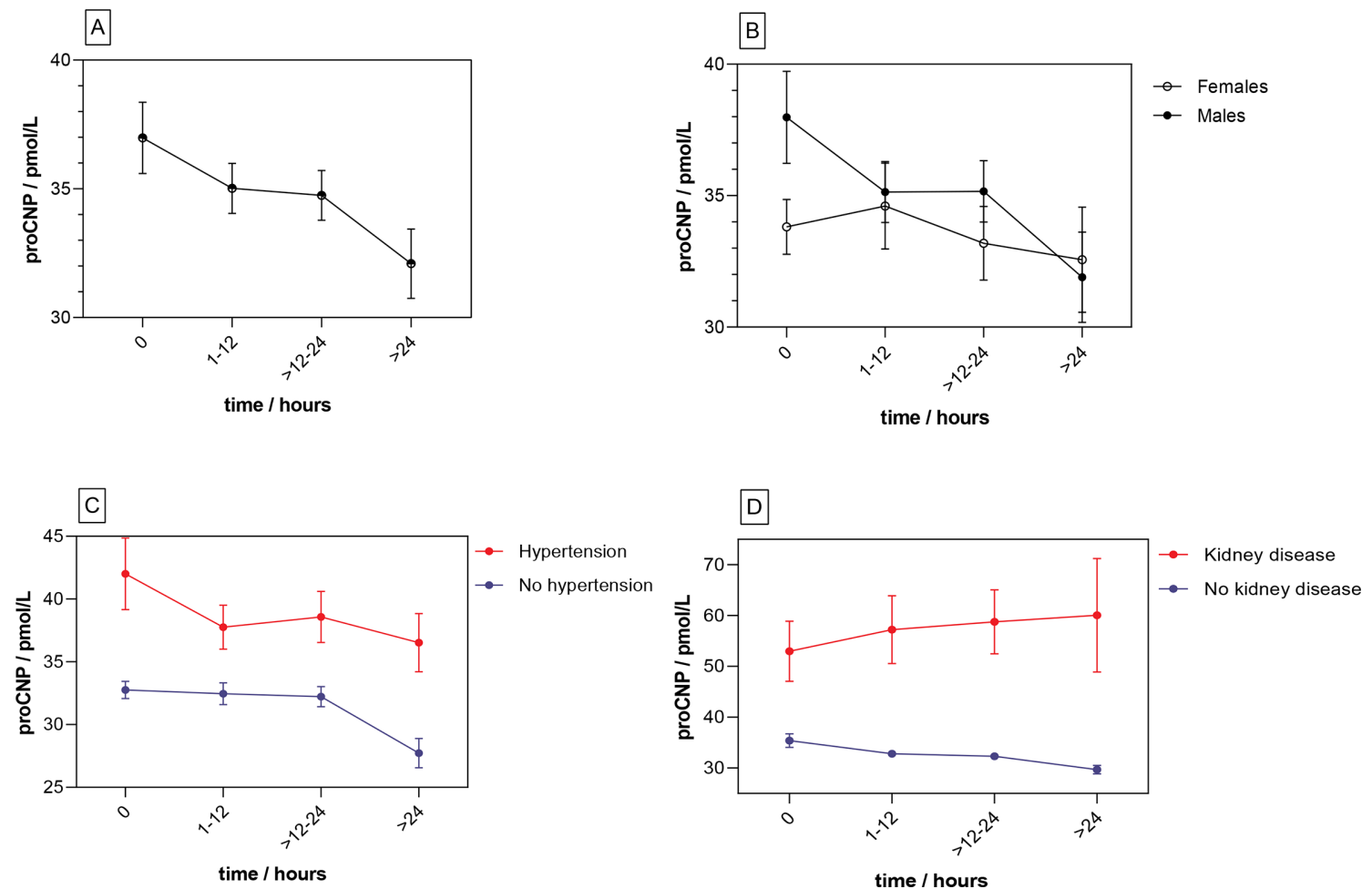

Figure 3 Longitudinal concentrations of pro-CNP in plasma. concentrations are shown as mean (point) and SE of the mean (error bars). Pro-CNP concentrations over time for 287 patients with STEMI are shown in section A. in section B, C, and D, these patients are grouped based on sex, hypertension, and chronic kidney disease, respectively. 


\section{DISCUSSION}

In this study, we report on a marked sex-specific prognostic information profile for pro-CNP measurement in patients presenting with an STEMI. A major advantage of our present approach comes from an independent establishment of a sex-specific pro-CNP reference interval prior to patient measurement. This allowed us to perform clinically meaningful divisions of normal, decreased or increased pro-CNP concentrations in plasma specific to sex, rather than testing differences only within the patient cohort as a whole (seeonline supplemental material for discussion of age groups).

In this cohort of consecutive patients with a verified STEMI, we show that $16.1 \%$ have increased concentrations of pro-CNP during the early phase of the myocardial infarction compared with the sex-specific and age-specific intervals. Interestingly, besides higher prevalence of CKD, we found a markedly higher prevalence of cardiovascular disease including hypertension in both sexes; diabetes mellitus and peripheral artery disease for female patients; and stroke for males among patients with increased pro-CNP. Our longitudinal analyses of a subgroup of the STEMI patients corroborates that the association to both CKD and hypertension is consistent even over time and is independent of sex, age and other cardiovascular diseases. A putative explanation for the linkage of hypertension and increased pro-CNP concentrations is the upregulation of CNP expression by vascular shear stress. ${ }^{21}{ }^{22}$ The positive association of pro-CNP and a vascular marker, sTM, for both sexes also support the relation of circulating pro-CNP with vascular stress. In contrast, the baseline associations of increased pro-CNP concentrations and diabetes, peripheral artery disease and stroke, respectively, are not statistically independent in longitudinal analyses. However, given the sex-specific pattern in the baseline findings and the limited number of patients with the respective diseases in longitudinal analyses, the results may be too preliminary to sufficiently conclude on the potential associations to diabetes, peripheral artery disease and stroke. Also, the statistical uncertainty of the suggested effect of sex and interaction of sex and time in longitudinal analyses calls for a cautious interpretation (see online supplemental material for further discussion of longitudinal analyses).

The risks of death within 30 days and 1 year were higher for female patients with increased pro-CNP concentrations-but not for male patients. This marked sex-specific association was confirmed when the mortality rate was analysed by increases of pro-CNP $\geq$ median, where proCNP proved to be an independent predictor in a model (model 1 in table 2) including two additional variables, age and plasma creatinine, which have previously established associations with NT-pro-CNP in plasma. ${ }^{23}$ To further test the prognostic potential of pro-CNP, we added plasma pro-ANP, tertiles of peak troponins, number of vessels affected and time from onset of symptoms to admission into a multivariable model (model 2). In this model, increases of pro-CNP were still independently associated with the risk of death, and the estimates were of similar size at both time points. Recent data on patients with STEMI found no independent prognostic value on mortality rate for NT-pro-CNP concentrations. ${ }^{8}$ However, that report differed from ours in several aspects including radioimmunoassay principle and duration of follow-up, and, importantly, plasma was sampled 4-6 weeks after admission in contrast to our real-time STEMI investigation. These differences make a direct comparison difficult.

Our results firmly suggest a sex-specific association with survival, where increased pro-CNP concentrations indicate a poorer prognosis in female patients. Previously, studies have shown that CNP acts as a more potent vasodilator in female porcine arteries ${ }^{24}$ and that the female sex hormone estradiol upregulates the expression of CNP in vascular endothelial cells. ${ }^{25}$ Furthermore, recent preclinical reports have convincingly pointed to a pivotal role of CNP and its receptors in the regulation of the microcirculation ${ }^{5}$ and in cardiac homeostasis. ${ }^{26}$ Taken together, these previous findings suggest that the CNP system is a critical modulator of vascular integrity and function including a more pronounced vasodilatory capacity in females that may be provided by female sex hormones. Clinical evidence shows that females display a sharp rise in the incidence of cardiovascular disease after menopause and that changes in sex hormones by complex mechanisms play a key role in the loss of vasoprotection. ${ }^{27}{ }^{28}$ Notably, postmenopausal females are at higher risk of coronary microvascular dysfunction and HFpEF compared with their male counterparts, ${ }^{29}$ and high concentrations of NT-pro-CNP have previously been independently linked to an adverse outcome in patients with $\mathrm{HFpEF}{ }^{9}$ In this perspective, we speculate that our observed sex-specific effect of increased pro-CNP concentrations in plasma of patients with STEMI partly reflects ongoing vascular dysfunction in females in particular and, hence, represents an independent signal of poor cardiovascular prognosis. However, there is a need for translational research to elucidate this association between increased pro-CNP in females with vascular complications and increased mortality rate. Furthermore, there is a paucity of reports examining a potential racial impact on concentrations of circulating pro-CNP-derived peptides. As the majority of Danish and Scandinavian population are Caucasian, it remains to be investigated whether our results can be extrapolated to other populations.

\section{Limitations}

While the number of patients with STEMI in the cohort is high, the follow-up period is relatively short. We examined only all-cause mortality as outcome in our follow-up multivariable Cox regression analyses, and other clinical endpoints, for example, cardiac readmission, were not tested. Hence, the number of events limits the number of possible covariates in the multivariable Cox regression analyses (model 3), and sex-specific estimates of 30-day mortality in this model should be interpreted cautiously. 
Moreover, this study focused on increased pro-CNP and the upper range of pro-CNP concentrations in plasma, whereas associations of decreased pro-CNP concentrations were not investigated. With regard to measurement of troponins in plasma, two different analytes (troponin $\mathrm{T}$ and troponin I) were measured at the two hospitals of inclusion. Thus, a combined variable of tertiles of peak troponins (discrete values of one to three) was included in the multivariable models with less quantitative information than the measured concentrations. Baseline biochemical analyses were performed on arterial plasma, whereas venous plasma was used from the reference population and in repeated measurements. A previous report has shown slightly lower plasma concentrations of NT-pro-CNP in arterial compared with venous plasma. ${ }^{30}$ Thus, in theory, our approach will underestimate the proportion of STEMI patients with increased pro-CNP concentration and the initial longitudinal decrease in pro-CNP concentration from baseline to the second time point (0 to $1-12$ hours).

\section{CONCLUSIONS}

We show here that increased pro-CNP concentrations in plasma from patients presenting with STEMI are associated with a higher all-cause mortality rate within 1 year among female patients with STEMI, whereas male patients display no such pattern. Moreover, we report that an increase of pro-CNP in the upper range of plasma concentrations ( $\geq$ median) in female patients is an independent prognostic marker of mortality at both 30 days and 1 year. The findings are remarkably specific for female patients, suggesting a different vascular phenotype beyond traditional measures of coronary artery flow compared with male patients.

\section{Author affiliations}

'Department of Clinical Biochemistry, Copenhagen University Hospital, Rigshospitalet, Denmark

${ }^{2}$ Department of Cardiology, Copenhagen University Hospital, Rigshospitalet, Denmark

${ }^{3}$ Department of Cardiology, Odense University hospital, Odense, Denmark

${ }^{4}$ Department of Clinical Immunology, Copenhagen University Hospital,

Rigshospitalet, Denmark

${ }^{5}$ Department of Medicine, University of Otago, Christchurch, New Zealand

${ }^{6}$ Department of Biomedical Sciences, Faculty of Health Sciences, Copenhagen University, Copenhagen, Denmark

Acknowledgements We are grateful to laboratory technicians Marie Ziebell Severinsen and Anne Truesen Asanovski for their expertise regarding pro-ANP and pro-CNP measurement in plasma.

Contributors Designed the study: PDM, MF, CH and JPG. Designed and conducted the STEMI cohort study: MF, OKLH, LH, JEM and CH. Undertook biochemical measurements: PDM, SRO, PIJ and JPG. Performed the data analysis: PDM, MF and TP. Wrote the manuscript draft: PDM. Revised the paper based on intellectual contribution: PDM, MF, OKLH, LH, JEM, PIJ, SRO, TP, CH and JPG.

Funding Research grants from Rigshospitalet.

Competing interests None declared.

Patient and public involvement statement Patients and/or the public were not involved in the design, or conduct, or reporting, or dissemination plans of this research.
Patient consent for publication Not applicable.

Ethics approval The study was approved by the Local Committee on Health Research Ethics (Copenhagen) (Ref. H-2-2014-110).

Provenance and peer review Not commissioned; externally peer reviewed.

Data availability statement Data are available on reasonable request. All data relevant to the study are included in the article or uploaded as online supplemental information.

Supplemental material This content has been supplied by the author(s). It has not been vetted by BMJ Publishing Group Limited (BMJ) and may not have been peer-reviewed. Any opinions or recommendations discussed are solely those of the author(s) and are not endorsed by BMJ. BMJ disclaims all liability and responsibility arising from any reliance placed on the content. Where the content includes any translated material, BMJ does not warrant the accuracy and reliability of the translations (including but not limited to local regulations, clinical guidelines, terminology, drug names and drug dosages), and is not responsible for any error and/or omissions arising from translation and adaptation or otherwise.

Open access This is an open access article distributed in accordance with the Creative Commons Attribution Non Commercial (CC BY-NC 4.0) license, which permits others to distribute, remix, adapt, build upon this work non-commercially, and license their derivative works on different terms, provided the original work is properly cited, appropriate credit is given, any changes made indicated, and the use is non-commercial. See: http://creativecommons.org/licenses/by-nc/4.0/.

\section{ORCID iDs}

Martin Frydland http://orcid.org/0000-0003-1543-8948

Ole Kristian Lerche Helgestad http://orcid.org/0000-0003-3847-8758

Pär I Johansson http://orcid.org/0000-0001-9778-5964

Jens Peter Goetze http://orcid.org/0000-0001-6356-3829

\section{REFERENCES}

1 Goetze JP, Bruneau BG, Ramos HR, et al. Cardiac natriuretic peptides. Nat Rev Cardiol 2020;17:698-717.

2 Sellitti DF, Koles N, Mendonça MC. Regulation of C-type natriuretic peptide expression. Peptides 2011;32:1964-71.

3 Stingo AJ, Clavell AL, Heublein DM, et al. Presence of C-type natriuretic peptide in cultured human endothelial cells and plasma. Am J Physiol 1992;263:H1318-21.

4 Nakao K, Kuwahara K, Nishikimi T, et al. Endothelium-Derived Ctype natriuretic peptide contributes to blood pressure regulation by maintaining endothelial integrity. Hypertension 2017;69:286-96.

5 Špiranec K, Chen W, Werner F, et al. Endothelial C-type natriuretic peptide acts on pericytes to regulate microcirculatory flow and blood pressure. Circulation 2018;138:494-508.

6 Bubb KJ, Aubdool AA, Moyes AJ, et al. Endothelial C-type natriuretic peptide is a critical regulator of angiogenesis and vascular remodeling. Circulation 2019;139:1612-28.

7 Parmar KM, Larman HB, Dai G, et al. Integration of flow-dependent endothelial phenotypes by Kruppel-like factor 2 . J Clin Invest 2006;116:49-58.

8 Prickett TCR, Doughty RN, Troughton RW, et al. C-Type natriuretic peptides in coronary disease. Clin Chem 2017;63:316-24.

9 Lok DJ, Klip IT, Voors AA, et al. Prognostic value of N-terminal pro $\mathrm{C}$-type natriuretic peptide in heart failure patients with preserved and reduced ejection fraction. Eur J Heart Fail 2014;16:958-66.

10 Sangaralingham SJ, McKie PM, Ichiki T, et al. Circulating C-type natriuretic peptide and its relationship to cardiovascular disease in the general population. Hypertension 2015;65:1187-94.

11 Pemberton CJ, Siriwardena M, Kleffmann T, et al. C-Type natriuretic peptide (CNP) signal peptide fragments are present in the human circulation. Biochem Biophys Res Commun 2014;449:301-6.

12 Lippert SK, Rehfeld JF, Goetze JP. Processing-Independent analysis for pro-C-type natriuretic peptide. J Immunol Methods 2010;362:32-7.

13 Felding P, Rustad P, Mårtensson A, et al. Reference individuals, blood collection, treatment of samples and descriptive data from the questionnaire in the Nordic reference interval project 2000. Scand J Clin Lab Invest 2004;64:327-42.

14 Mark PD, Hunter I, Terzic D, et al. Processing-Independent proANP measurement for low concentrations in plasma: reference intervals and effect of body mass index and plasma glucose. Clin Chem Lab Med 2017;56:132-7.

15 Obling L, Frydland M, Hansen R, et al. Risk factors of late cardiogenic shock and mortality in ST-segment elevation myocardial infarction patients. Eur Heart J Acute Cardiovasc Care 2018;7:7-15. 
16 Thygesen K, Alpert JS, Jaffe AS, et al. Third universal definition of myocardial infarction. Circulation 2012;126:2020-35.

17 Rehfeld JF, Goetze JP. The posttranslational phase of gene expression: new possibilities in molecular diagnosis. Curr Mol Med 2003;3:25-38.

18 Hunter I, Rehfeld JF, Goetze JP. Measurement of the total proANP product in mammals by processing independent analysis. $\mathrm{J}$ Immunol Methods 2011;370:104-10.

19 Solberg HE. The IFCC recommendation on estimation of reference intervals. The RefVal program. Clin Chem Lab Med 2004;42:710-4.

20 3.5.1. RDCT. A language and environment for statistical computing. $R$ Found Stat Comput2018;2.

21 Chun $\mathrm{TH}$, Itoh H, Ogawa Y, et al. Shear stress augments expression of C-type natriuretic peptide and adrenomedullin. Hypertension 1997;29:1296-302.

22 Zhang Z, Xiao Z, Diamond SL. Shear stress induction of C-type natriuretic peptide (CNP) in endothelial cells is independent of NO autocrine signaling. Ann Biomed Eng 1999;27:419-26.

23 Prickett TCR, Olney RC, Cameron VA, et al. Impact of age, phenotype and cardio-renal function on plasma C-type and B-type natriuretic peptide forms in an adult population. Clin Endocrinol 2013;78:783-9.
24 Barber DA, Burnett JC, Fitzpatrick LA, et al. Gender and relaxation to C-type natriuretic peptide in porcine coronary arteries. J Cardiovasc Pharmacol 1998;32:5-11.

25 Prickett TCR, Barrell GK, Wellby M, et al. Effect of sex steroids on plasma C-type natriuretic peptide forms: stimulation by oestradiol in lambs and adult sheep. J Endocrinol 2008;199:481-7.

26 Moyes AJ, Chu SM, Aubdool AA, et al. C-Type natriuretic peptide co-ordinates cardiac structure and function. Eur Heart $J$ 2020;41:1006-20.

27 Vitale C, Mendelsohn ME, Rosano GMC. Gender differences in the cardiovascular effect of sex hormones. Nat Rev Cardiol 2009;6:532-42.

28 Mendelsohn ME, Karas RH. Molecular and cellular basis of cardiovascular gender differences. Science 2005;308:1583-7.

29 den Ruijter HM, Haitjema S, Asselbergs FW, et al. Sex matters to the heart: a special issue dedicated to the impact of sex related differences of cardiovascular diseases. Atherosclerosis 2015;241:205-7.

30 Palmer SC, Prickett TCR, Espiner EA, et al. Regional release and clearance of $\mathrm{C}$-type natriuretic peptides in the human circulation and relation to cardiac function. Hypertension 2009;54:612-8. 